\title{
Nurturing the West from a Well in the East: The Integration of East Asian Spiritual Philosophy in Western Conflict Transformation
}

\author{
Jack B. Hamlin ${ }^{1}$ \\ ${ }^{1}$ National University, USA \\ Correspondence: Jack B. Hamlin, Lead Faculty for Alternative Dispute Resolution Studies, School of Professional \\ Studies, National University, La Jolla, California, USA. E-mail: jhamlin@nu.edu
}

Received: September 8, 2014 Accepted: October 15, 2014 Online Published: December 23, 2014

doi:10.5430/wjss.v2n1p42 URL: http://dx.doi.org/10.5430/wjss.v2n1p42

\begin{abstract}
The manner in which Western Culture addresses conflict has entered an evolving age. First embracing Alternate Dispute Resolution as a powerful tool, the culture has recognized and begun to move toward a Conflict Transformation model. The Conflict Transformation is not new or unique and, in part, is an assimilation of East Asian Spiritual Philosophies.

This paper identifies and compares the manner in which the "Chinese Religion," comprised of the integrated philosophies of Taoism, Mahayana Buddhism, and Confucianism, has impacted the evolution of the Conflict Transformation model in the United States, focusing on the need to recognize and understand the linear aspect and not merely its manifestations, or trigger events.

Focusing on the relevant precepts of Chinese Religion, the paper addresses the endorsement of a more complete, if not complex, approach which strives toward a transformation rather than closure to conflict; a remedy rather than a bandage. The process for transforming conflict, while adaptable, relies on recognition of a conflict, defining and acceptance of the source, manifestations of the conflict or trigger events, acknowledgment of who are the stakeholders and its degree and impact upon each. In so doing, settlement of the issues arrives through transformation, utilizing circumstantial burden and personal investment based in a balancing of emotional, intellectual, physical and spiritual components. The process can only be accomplished effectively by empowering disputants with a voice and choice creating a vantage for each stakeholder, relying not on compromise, but collaboration.
\end{abstract}

These concepts place the outcome in the hands of the stakeholders to understand, work through, accept, and grow personally and socially from conflict.

Keywords: Conflict Transformation, Mediation, Restorative Justice, Buddhism, Taoism, Confucianism

\section{Introduction}

Asian spiritual philosophies have flowed from a vast well spring of ancient traditions and history for many centuries. What has been referred to as the "Chinese Religion"," the blending of Taoism, Mahayana Buddhism, and Confucianism, continues to provide a source of refreshing philosophy and direction to those who follow its precepts (Barrett, 2005; Gho, 2009). While the institutional and political West was eyeing the East with distrust during the Red Scare of the Cold War Period, Chinese Religion was explored by such spiritual philosophers as Pierre Teilhard de Chardin (1960, 1965) and Thomas Merton (1967, 1968) and gained a foothold as alternative spiritual life philosophies in the West. Although initially overlooked, misinterpreted or viewed with skepticism by the West, many of these philosophies have found their way into the Western world and through assimilation have become forms of alternative staples within the beliefs, values and actions within many Western models. The compatibility of an Eastern spirituality and Western empiricism has been addressed in such seminal works as, Tao of Physics (Capra,

\footnotetext{
${ }^{1}$ For the purpose of this paper, the phrase "Chinese Religion" will refer to various aspects of Taoism, Mahayana Buddhism, and Confucianism philosophy. In the truest sense, these are not religions, but philosophies which have been raised to the level of religious practice. Where the philosophies are silent or diverge will be noted.
} 
1983), and in other settings such as the use of Sun Tzu's Art of War as model for Western business (Chen, 2002).

With the advent of rapid globalization, the applications of Chinese Religious ideology and values have been integrated into a transitional form of dispute resolution. It has redirected the rubric in the process once strictly referred to Alternative Dispute Resolution (ADR), to evolve into the more contemporary paradigm of Conflict Transformation (CT). Despite the influence of Eastern principals, their relevance and practice have become a challenging fit in the mindset of the Westerner in a restorative practice paradigm. Simply put, at times it is difficult to implement the flow between internal and external individual with a cultural belief system which has embraced and ingrained the extrovert; how the individual views, meets and impacts the external world through some type of control. This model, however, can be defined, established and applied.

In order to do so, this paper will present a brief overview of the Chinese Religion, establishing and identifying the salient ideologies. Second, an understanding of the ADR movement in the West as a practical model for conflict resolution is presented. As a final stage, the discussion of the transition from resolution to transformation in conjunction with precepts of Chinese Religion suggesting a path of metamorphosis; from a finite task oriented model with a beginning, middle and end, to one which views conflict as an opportunity to collaborate, grow and transform. Concluding this discussion are some thoughts on the direction of Conflict Transformation and the need to be willing to view other forms as effective, and the opportunity and willingness to experiment with those ideologies.

\section{Chinese Religion "101"}

To suggest this paper will address the East Asian philosophy in any depth would be unbridled hubris on the part of the author. So I will not. As the title suggests, however, the philosophies which are the cornerstone of Chinese Religion (Taoism, Mahayana Buddhism, and Confucianism) flow from a very old metaphorical well spring of knowledge and tradition, into which we will dangle our metaphorical Western toes.

Merton wrote:

"Oriental religions, while they may differ in philosophy and belief, have a way of interpenetrating quite freely with one another. Chinese Buddhism is fact an amalgam of Taoism and the "Great Vehicle" (Mahayana Buddhism) of India. The Taoism that still goes by that name is in fact much further from the original Taoism of Lao Tzu than Zen Buddhism, which preserves intact the living thought of the Tao Te Ching, while popular Taoism is a hodgepodge of quasi-magical rites, folklore, and superstition. As for Confucianism, it is certainly not a religion in the same sense as Christianity. Confucianism is less a "faith" than a sacred philosophy, a way of life based on archaic religious wisdom, and capable of coexistence with some other faith in religious revelation (Merton, 1967, pp. 46-47).

The dominant scholarly view treats Chinese religion not as "a theological entity," but a "cultural complex" that celebrates the life-course of individuals in the Chinese community, a participatory religion of ethnic rites of passage that defines the spatial-temporality of the Chinese life-world (Saso, 1985:344). Scholars have introduced a wide range of practices into their analysis of Chinese religion and criticized the flawed Eurocentric definition of Chinese religion as consisting of Taoism, Buddhism and Confucianism and the residual category of popular religion, and affirmed the radical syncretism of Chinese religion that fuses all [three] categories and more. (Goh, 2009; Barratt, 2005)

The West finds the "interpenetrating" nature of Taoism, Buddhism, and Confucianism, disconcerting and inconsistent with its ideas of the relatively fine lines of demarcation between the major faiths (Christianity, Islam, and Judaism), while missing the irony each acknowledges the existence of God, the same in each faith. What follows then is only the briefest of overviews of the three principal philosophies.

\subsection{Taoism}

The tao that can be told

is not the eternal Tao

The name that can be named

is not the eternal Name.

The unnamable is the eternally real.

From Chapter 1, Tao Te Ching

So with the introduction to its dualistic nature of existence and nonexistence, begins the paradoxical enigma of the 81 verses of the Tao Te Ching (pronounced Dao De Jing) which, literally translated is "The Way" (Tao) and "The 
Virtue" (Te) and Ching, which simply means "Classic;" as in a classic text, such as the Bible, Qu'ran or Torah. While historically credited with writing the Tao Te Ching, most contemporary scholars recognize Lao Tzu, from the Zhou (Chou) dynasty, as merely name given to a number of individuals who over the centuries developed the 81 verses from which the Taoist philosophy has its foundations. The sixth century, B.C.E. is only a point of convenience for establishing the writings of the Tao Te Ching, which most view as an evolving philosophy, dating back at least a millennium before. Russell Kirkland opines in his book Taoism, the Enduring Traditions, "Taoism must be identified, in the first instance, in terms of historical heritage," (Kirkland, 2004, p.12), which might explain the literally thousands of translations and interpretations of the Tao Te Ching.

In the introduction to his text, Everyday Tao: Living with Balance and Harmony, Ding Ming-Dao attributes several qualities of those who follow the Tao. While simplistic, the qualities offer the reader a glimpse into the nature of Taoism:

- Simplicity: The Taoist seeks a simple life, conservation and contentment in maintaining a personal equilibrium between spirit, emotion, physical and intellect.

- Sensitivity: The Taoist is observant of others, avoiding aggression and helping those in need. A love of Nature and the lessons to be learned are often metaphors for the Taoist lifestyle.

- Flexibility: The Taoist does not belief in absolutes. Choices need to be made on circumstances rather than preconceptions.

- Independence: The Taoist refuses to be limited by fads, trends, dictates, political agendas or popular morality. Wisdom and experience are the guideposts.

- Inner Focused: The Taoist focuses on an inner direction, accepting who he or she is and taking of advantage of who he or she is rather than addressing life's journey as someone he or she is not.

- Cultivated: The Taoist refines his or her life simplicity, observation, and action to follow the Tao more completely.

- Disciplined: The Taoist takes orderly action toward specific goals.

- Joyous: The Taoist seeks an absence of fear and a journey toward living within the flow of the Tao.

Perhaps one way to envision Taoism is a life of discovery of something which can never be discovered, less than a journey of the intellect, but rather one in which all aspects of one's being are of equal importance; an equilibrium of the spirit, the intellect, the physical, and the emotion (Merton, 1967, p. 74).

J.W. Freiberg comments on the epistemological elements of Taoism. "First, [is] ontological elements surrounding Unity; Opposition; Becoming; Circularity; Relativity; Ch'i (life energy); and Magic. Secondly, the spiritual elements detailing Naturalness; Emptiness; Quietude; Concealment; Intuitive Knowledge; and Center. Finally, an ending on action elements that consist of Not-Doing; Correctness; Indirectness; Yielding; Initiative; Protraction" (Freiberg, 1975). The three blended corners of Freiberg's triad highlight the full Taoist character; the self, the world, and all actions comprising the two. This mindset is key to Taoist self-actualization, acceptance, and responsibility; true components which create a ready vehicle to address and transform conflict.

The conceptual flow of the Tao can often be attributed to its connection with all things. The five elements that generate the Tao are fire, water, wood, metal, and earth. These elements create the flow of all things as they combine, react, and regenerate the principles to emanate. The symbol that may represent this philosophy best is the yin-yang. The outer circle represents everything as the black and white interior symbolizes two opposite energies that intertwine to create totality through continual movement, blending birth, death and re-birth as a continuum instead of finite events. As knowledge becomes less and nothing becomes more, the Tao feeds and presents the results of all things. "The world is a spiritual vessel, and one cannot act upon it; one who acts upon it destroys it". Kirkland adds, "from the perspective of classical Taoism, Western humanism makes the mistake of assuming that the ability to intervene in life's events translates into a moral duty to do so" (Kirkland, 2001). Accepting conflict is inevitable, the Tao takes the events and works through them taking into account on a level which includes the effects on the individual and universe and back again.

${ }^{1}$ Chapter 29, Tao Te Ching 


\subsection{Buddhism}

Abandon negative action;

Create perfect virtue;

Subdue your own mind.

This is the teaching of the Buddha

\section{The Buddha}

The man known to us as Buddha lived in Nepal in the sixth century B.C.E. Originally named Gautama, he was a prince who lived a shelter life, knowing nothing of sickness, death or human suffering. When confronted with these harsh realities as a young man, he left his comfortable world for a life which sought out the cessation of suffering. For six years he traveled the valley of the Ganges River learning from various religious teachers, but it was not until he sought quiet under the Bodhi tree he experienced enlightenment. From then on he was known as the Buddha, or the "awakened one." (Hagen, 1977).

Mahayana Buddhism has its origins in China during the $2^{\text {nd }}$ Century during a time when the teachings (dharma) of the Buddha had become wide spread among those away from monastic practices, availing the life philosophies to quasi-laity. Mahayana Buddhism is potentially the most widely practiced of the East Asian Philosophies. It seeks the idea of peace and the path traveled to obtain it. It is this rationalized peaceful path that has gained the attention of both scholars and legal community. The collective of Buddhism doctrines perform under the Four Noble Truths which remain common to all Buddhism: existence is suffering (Dukkha); suffering has a cause, namely craving and attachment (Dukkha Samudaya); there is a cessation of suffering (Dukkha Nirodha); and the path to the cessation of suffering (Dukkha Nirodha Gamini), through the "eightfold path." The eight fold path consists of right views, right resolve, right speech, right action, right livelihood, right effort, right mindfulness, and right concentration. Buddhism characteristically describes reality in terms of process and relation rather than entity or substance (Chodron, 2001).

Suzuki tells us, "Strictly speaking, there cannot be a philosophy of suchness, because suchness defies a clear-cut definition as an idea. When it is presented as an idea it is lost; it turns into a shadow, and any philosophy built on it will be a castle in the sand... [Buddhism] is not explainable by mere intellectual analysis. As long as the intellect is concerned with words and ideas, it can never reach [Buddha consciousness]."(Suzuki, 1955). "It goes without saying that [Buddhism] is neither psychology nor philosophy" (Suzuki, 1952) ${ }^{1}$. A simplistic distillation of Buddhist ideology is then seeking the cessation of suffering; one's own suffering and the suffering of others.

Taoism and Buddhism share many common grounds that support a workable platform to transform conflict. "Taoism is about "the way," albeit a bit difficult to discern exactly what this means. The Tao is the ultimate creative principle of the universe. All things are unified and connected in and through the Tao" (BBC, 2009). The Tao may be considered more applicable to conflict transformation because it has a slightly focused view on psychological constructs; turning inward and really on the true self before addressing the external; in this case, conflict. It is a path that has vision and is followed, granting access through the Tao. The beliefs of Buddhism and Taoism incorporate a cause and effect doctrine that utilizes all aspects of life as we understand it and a glimpse of the potential beyond. A spiritual realm, however, is only a portion of how the two philosophies blend into action, the self, and universe. Confucius completes the triangle.

\subsection{Confucianism}

Recompense injury with justice, and recompense kindness with kindness

\section{Confucius}

The doctrine of Confucianism was a product of the time, circumstance, and belief. As the newest evolution or addition to Chinese Religion, Confucius was credited as a teacher, writer, editor, politician and philosopher who lived in China between 551 and 479 B.C.E. He found err in the direction of humanitarian rule or lack thereof. He found that training through channels of respect and virtue lead to peace inward and outward. The peace that was sought was an element missing not only in the rule of the government but in each individual and their community. The Confucian focus of humanity promotes the inner peace and understanding through actualization, creation, and cultivation of the self. This is often accomplished through ethics maintenance proficiencies simplified by Kurtis Hagen in the following definitions:

\footnotetext{
${ }^{1}$ Suzuki addresses Buddhism from the school of Zen, which has been replaced here simply with Buddhism.
} 
- Ren: A comprehensive virtue that attempts to see things from other people's perspectives, and then to do one's best for them with that in mind.

- Yi: A sense of appropriateness that focuses principally on what is right or fitting.

- Li: An appropriate ritualistic behavior in all circumstances, one should be conscientiously attentive to detail, and sensitive to what is most appropriate to the situation.

The transposed behaviors are not limited directly to the self in terms of respect. Those who practice Confucianism become more than practitioners because the maintenance of the philosophy is directed toward mutual respect. The respect is also a generational adhesive as filial piety bonds traditional relationship appropriately. This sense of extended and reciprocated respect in theory creates the totality of peace and understanding.

An often overlooked component to Confucianism is that it functions on non-theistic principles. "On spirituality, Confucius said to Chi Lu, one of his students, that "You are not yet able to serve men, how can you serve spirits?" (Sinaiko, 1998) Although, easily compared to religious philosophies as a result of the use of rituals and presentation it remains based in humanities. This aspect has, at the same time, complicated and simplified its understanding for many outside of the doctrine. Author C.K Yang adds, "Confucianism is religious, even if non-theistic, in the sense that it "performs some of the basic psycho-social functions of full-fledged religions, in the same way non-theistic ideologies do." (Yang, 1961) As with many Asian Philosophical ideals, there are components that are applicable to many platforms. Confucianism has an intended result of social harmony. This can be applied to a stratum spanning individuals, communities, states, and the globe. With theories so sizable and intense, the association of its origin is often considered in adapting its logic. The Western culture accepts portions of Confucianism anonymous to its origin. As an exercise in power, the West often rejects total social harmony concepts because of the class structure. In opposition, Western models of conflict transformation accept the virtuous self-empowering concepts to demonstrate behavior, respect, and harmonious transition throughout the conflict process.

Just as Taoism centers on the self, Confucianism is defined as a practice focused on social practice. It completes a cycle needed to move through conflict with a focus on values and ethics. Within these disciplines, the belief and execution of harmony (he) is actualized. It is Confucius' harmony that allows the Buddhist's flow and the Taoist's self to transform conflict. The essence of harmony can occur with the self but it is an adhesive connecting and maintains thought, spirituality, and relationship. "The concept of harmony can be used to explain five communication rules: self-restrain/self-discipline, indirect expression of disapproval, saving or making face for counterparts, reciprocity, and emphasis on particularistic relationships, in Chinese conflict management (Chen, 2002). These communication "rules" have promise as an application to Western Conflict Transformation practices. Contextual application in Western practice, however, is compartmentalized for the purpose of conflict transformation as procedural, straying from the theoretical and overriding lifestyle practice of the Chinese Religion. "It is argued that East Asian communication patterns differ from those of North America because of the Eastern emphasis on social relationships as opposed to the North American emphasis on individualism. This East Asian preoccupation with social relationships stems from the doctrines of Confucianism, which considers proper human relationships to be the basis of society. The cardinal principle of Confucianism is humanism, which is understood as a warm human feeling between people and strongly emphasizes reciprocity. As a philosophy of humanism and social relations, Confucianism has left a strong impact on interpersonal relationships and on communication patterns."(Yum, 1988).

In a very generalized sense of their respective schools of thought, Taoism, Buddhism, and Confucianism all revolve around the similar concepts of self, world, and spirituality; more specifically peace inward and out. The process follows through recognition, acceptance, confrontation, adaptation, and peace. It does so by incorporating a cause and effect doctrine that utilizes all aspects of life as we know it and those of which we are unaware. A spiritual realm is only a portion of how the theories blend into action, the self, and universe. Chuang pieces together these ideals that have cultured a multitude with simple causation; a questioned flow of life and an answer that is a result of this flow. Chuang adds, "the Zen idea of human independence is to participate in each moment of living, achieve full independence in one's thought and action, and not to place oneself in conflict with nature or other people" (Chuang, 2002). Such positioning creates an ideal condition for conflict transformation and growth. The age of transforming conflict can become a powerful era in Western culture. Conflict transformation, as opposed to dispute resolution, draws deeper from the well, going beyond typical intellectual fact finding techniques to accept and embrace emotional, spiritual, cognitive and physical discovery to complete a more satisfied position when issues are transformation. 


\section{From Resolution to Transformation}

\subsection{What is Conflict?}

Conflict Resolution is neither new, nor unique to anyone culture. If conflict is defined as an incompatibility of needs, interests, and/or goals between two or more stakeholders, it takes away the preconceived notion conflict is "bad." (Coltri, 2004) Conflict is neither good nor bad. It is the manner in which it conflict is addressed, not necessarily resolved, which can be very bad (violence and war) or very good (collaboration and creation). An individual, from any culture, is faced with perhaps hundreds of conflicts each day, and most are negotiated without a second thought.

For example, I am hungry and I have money, but no food. The shop has food and needs money to sustain itself. The conflict is easily resolved, I give them money, and the shop gives me food. Or consider, I need a parking space and there are none in the lot. An individual parked wants to leave the lot, but my car blocks their way. I move my car, the individual backs up and leaves, I take the now empty parking space. These two examples highlight the proposition that the mere incompatibility of needs, interests and/or goals faces us every day on many levels, and our cultural training, our socialization, allows us to resolve these nearly instantly and with nothing more than a passing thought

But now consider the two examples in this light. I am hungry and go into the shop which has food, say sandwiches. There is a menu on the wall which indicates a turkey sandwich for $\$ 5$ and I have $\$ 5$ to purchase the sandwich. I order the sandwich and I am asked if I want, "everything on it," and I reply "yes." When the sandwich is completed, the shopkeeper tells me it will be $\$ 8$; the extra cost is for the "everything on it." Now, the simple conflict of purchasing food to satisfy my hunger, has escalated, and so too do the options for resolving it. I am still hungry, but I am unwilling, or perhaps unable, to pay the extra hidden cost. Or back to the parking lot, suppose another driver pulls up behind me. He wants the space about to open up too, and is unwilling to allow me to back up. There is now a stalemate. One driver wants to leave, and two drivers want the space. Once again, the conflict escalates, and the options generally begin to spiral, potentially, toward "bad" resolution.

Although conflict may initially present itself as benign, additional variables can enlarge the conflict, and therefore increases the manner, or methods, in which the conflict is resolved; for good or ill. This is where the concepts of $\mathrm{ADR}$ and $\mathrm{CT}$ find their niche.

\subsection{What is Alternative Dispute Resolution?}

When addressing the concept of ADR, generally the focus is on such processes as mediation, arbitration, or a facilitative hybrid of the two. The term alternative in this context and Western culture in general, refers to something other than the litigation process. ADR is not, however, a new process or concept in Western culture. ${ }^{1}$ Forms of ADR can be found in colonial America (Goldberg, Sanders \& Rogers, (1999), and the first codification of a form of ADR process to be used dates back to 1888 , in which voluntary boards of arbitration were created to resolve controversies between railroads and their unions to avoid disrupting transportation ${ }^{2}$. ADR began to experience a movement into the mainstream of dispute resolution in the 1970's as a response to protracted and expensive litigation (Coltri, 2004). It was in the 1990's, however, ADR first received acknowledgement on the federal level with the passage of the Administrative Dispute Resolution Act of 1996, and the Alternative Dispute Resolution Act of 1998. The U.S. Attorney General's Order Promoting the Broader Appropriate Use of Alternative Dispute Resolution Techniques was issued in April, 1996, in the first formal endorsement of ADR, followed the Presidential Memorandum on ADR dated May 1, 1998.

ADR has found a place within family courts mediations, union disputes, employer-employee grievances, and contract interpretation disagreements. But as the name implies the process is focused on resolution. It may fail to take into account source or sources of the conflict, stakeholder validation and input, long-term consequences and future impacts. And at the end of the institutional process, hanging Damocles-like, is the fickle sword of litigation, often times forcing an involuntary resolution. In an expedited world of judicious resolution of one size fits all, rarely are the stakeholders content with the outcome, even when they "prevail."

\subsection{Conflict Transformation: The Alternative to ADR}

At the same time ADR was experiencing a rise in popularity, another process was quietly and surreptitiously beginning to grow. Developed from the peacebuilding theories and practice of Johan Galtung in Switzerland, and

\footnotetext{
${ }^{1}$ While recently viewing Eastwood's film, J. Edgar, about the life and times of FBI Chief, J. Edgar Hoover, the author observed the Hoover character reading the newspaper, circa 1935, and the back headline reads: Text of Mediation Board's Report to the President on Ways to Settle the Textile Strike.

2 Statutes at Large of the United States (1988) 25:501.
} 
John Paul Lederach of Eastern Mennonite University, conflict transformation approaches differ from those of ADR. Whereas conflict resolution approaches seek to move conflict parties away from zero-sum positions towards positive outcomes, often with the help of external actors, conflict transformation involves transforming the relationships that support conflict. It differs from ADR approaches in that it recognises "that contemporary conflicts require more than the reframing of positions and the identification of win-win outcomes. The very structure of parties and relationships may be embedded in a pattern of conflictual relationships that extend beyond the particular site of conflict. Conflict transformation is therefore a process of engaging with and transforming the relationships, interests, discourses and, if necessary, the very constitution of society that supports the continuation of violent conflict $^{1}$ (Miall, 2004; Lederach $^{2}$ 1995, 1997, 1999, 2003, 2005; Lederach \& Sampson, 2000; Lederach \& Jenner, 2002).

Conflict Transformation draws from the Western well such forgotten and diluted concepts as responsibility, harm (in a non-litigation sense), empathy, apology, forgiveness, and reconciliation. Like ADR it creates a personal involvement through choice, granting a control to the stakeholders. Unlike ADR, however, conflict transformation found in such processes as restorative justice, peace circle or circle process (Hamlin \& Darling, 2012), and victim-offender reconciliation mediation, has a major difference; reparation of relationships (Zehr, 1990, 2002). These processes recognize conflict has the potential to manifest as a triggering event (or events) which result in a harm. Left unrepaired, there becomes the potential of greater future harm. The parties to the conflict are not only the affected party or parties, and responsible party or parties, but a community from which various stakeholders emerge.

For example, teen alcohol and drug abuse creates a conflict within the community. The triggering event may be teen drunk driving, with an injury or fatality. The responsible party is the teen who drove under the influence and caused an injury, the affected party the individual injured. Who are the emerging community of stakeholders? Friends and family of the two immediate parties, law enforcement personnel who necessarily become involved, school administrators, teachers and students, employers and fellow employees, medical personnel (emergency and hospital), and so forth and so on. In a traditional model, the responsible party is charged, represented by counsel, appears in court, there may or may not be a trial, if guilt is found, a sentencing in which the affected party and perhaps a few close to the affected party make an impact statement, and the teen is sent to a incarcerating facility, where ostensibly he or she will be rehabilitated. Often the responsible party is clueless to the process in which she or he as fallen into ("Yes, your honor, I understand" is arguably the least voluntary and knowledgeable statement made in court). The affected party is less an integrated part of the process than a collateral piece. ${ }^{2}$ Often, based upon the degree of severity of the harm, the affected party knows nothing of the outcome of the process. And the community, well it is left to its own devices, and in attempts to curtail such future occurrences maybe harsher laws are enacted, and punishments imposed. But for the most part, the community is disenfranchised and isolated. Frustration turns to anger, and the anger manifests itself in violence (just read a dozen or so posts on news blog sites after the Aurora, Colorado theater shootings or the Oak Creek, Wisconsin Sikh Temple shootings). The powerlessness of an affected community cries out in anger for revenge and retribution in a near emotional and spiritual bloodlust and does violence to itself.

Now take the same example from a conflict transformation process perspective; victim-offender reconciliation model $^{3}$. A facilitator first meets with the responsible party to determine whether or not he or she is ready to take responsibility for the harm. Not until this is established would the affected party be approached. When the parties choose to move forward voluntarily, a meeting is arranged. The meeting can be one on one, or all those affected; the community. The parties share stories; what led up to the harm, the actual harm, and the consequences of the harm. The parties then have an opportunity ask each other questions, explore the root cause for the harm, and what to do to grow from harm; prevention from repeat occurrences by the responsible party and from within the community. The parties collaborate to transform the conflict and ensuing harm. Each stakeholder is valued, heard and recognized. In so doing, the stakeholders own the resolution, recognizing there may be much work to be done to complete the transformation to a point of resolution, but willing nonetheless.

\footnotetext{
${ }^{1}$ For the purpose of this paper, the word violence is used in a contemporary meaning which includes not only physical violence, but addresses violence to the emotional, intellectual and spiritual nature of the individual.

2 In California, the Victim of a criminal act is referred to as the "Complaining Witness," while the People of the State of California are the "victims."

3 The process works in tandem with the justice industry, so regardless of the outcome between affected and responsible party and community, incarceration probably will not be avoided.
} 


\section{Drawing from the Well}

It would appear, with the advent of ADR and the evolved form of Conflict Transformation, Western Culture may well be on the way to an evolution in the manner in which it addresses conflict, but this position may be prematurely overly optimistic at this point. The fact Western Culture demonstrates an interest in ADR and CT indicates it has a thirst for something better...the old well of litigation from which it has drawn is brackish, and no longer palatable. So why is there is resistance to accept CT as a cultural mindset?

First, perhaps the use of ADR and CT is the exception, not the norm. Western Culture continues to rely on a justice industry which produces anything but justice. It is an ingrained industry, one which is "familiar." Not its processes, but it use. To move away from a thousand year old system of justice, regardless of its flaws, is frightening and monumental. The evolution, and there will be one, will take time. It will take work and patience, and the input from all those who are affected by it. Which leads to a second point.

Western Culture, as previously noted, is a culture of reactive extroversion. Horace Greely's famous, "Go west, young man," has been taken to heart as a near mantra of divine providence for Western Culture. If a conflict presents itself, do away with it. Never stop, keep moving forward, go through obstacles, take no prisoners. It is not a culture which respects or engages in true introspection when confronted with conflict...conflict is the enemy, conflict is bad and therefore must be met with all resources to defeat it.

With the growth of ADR and CT, Western Culture is beginning to recognize a move toward introspection, but it is still reactive; and reactive to the manifestation of the conflict which is generally harm. At that point, it is repairing damage and trying to heal rather than prevention and true transformation. In order to truly adopt a restorative and transformative process to address conflict, will take cultural shift; one which is as equally as satisfied with experiencing the percolating spring introspection, as it is in the consequential vastness of an ocean of opportunities to transform conflicts.

Western Culture has taken a few satisfying sips from the Eastern well, in the form of ADR and CT, but as with all things we tend to gulp. It is time to savor what comes from the spring and instead of allowing our attempts at transformative processes to become simply another institution.

Developing practices of mindfulness based in the dualistic nature of the Tao meant to encourage a view of all perspectives, Buddhist practices which encourage a cessation of suffering for all, and a Confucius orientation based on the intertwined relationship of mutual respect of the individual with society are direction of the journey.

And once this has been started, then perhaps it will be time for a splash in the Western face from the equally refreshing African well of Ubuntu.

\section{Acknowledgements}

I would like to acknowledge the literature search conducted by National University student, Chad Heimbach, whose work was instrumental in the completion of this article.

\section{References}

Barrett, T. H. (2005). Chinese Religion in English Guise: The History of an Illusion. Modern Asian Studies, 39(3), 509-533. http://dx.doi.org/10.1017/S0026749X04001659

Capra, Fritjof. (1983). The Tao of physics: an exploration of the parallels between modern physics and Eastern mysticism. Boulder: Shambala.

Chen, G. M. (2002). The impact of harmony on Chinese conflict management. In Chen, G. M., \& Ma, R. (Eds), Chinese Conflict Management and Resolution (pp. 3-18). Westport: Ablex Publishing.

Chen, Guoquan. (2005). An organizational learning model based on western and Chinese management thoughts and practices. Management Decision, 43(4), 479-500.

Chodron, Thubten. (2001). Buddhism for Beginners. New York: Snow Lion Publications.

Freiberg, J. W. (1975). The Taoist Mind: A Case Study in a Structure of Consciousness. Sociological Analysis, 36(4), 304-322. London: Oxford University Press. http://www.jstor.org/stable/3710519 
Goh, D. P. S. (2009). Chinese Religion and the Challenge of Modernity in Malaysia and Singapore: Syncretism, Hybridisation and Transfiguration. Asian Journal of Social Science, 37, 107-137. http://dx.doi.org/10.1163/156853109X385411

Hagen, K. (2007). Confucian key terms. Retrieved from http://faculty.plattsburgh.edu/kurtis.hagen/keyterms_ren.html

Hagen, Steve. (1977). Buddhism, Plain and Simple. New York: Broadway Books

Hamlin, J. B., Darling, J. (2012). Use of Peace Circles in Large-Scale Community Conflict: A Case Study. Conflict Resolution Quarterly, 29(4), 403-419. http://dx.doi.org/10.1002/crq.21048

Kirkland, Russell. (2004). Taoism, the Enduring Traditions, Rutledge. p. 12.

Kirkland, Russell. (2001). Responsible Non-Action in a Natural World: Perspectives from the Nei-yeh, Chuang-tzu, and Tao-te ching. In Norman J. Girardot, Liu Xiaogan, \& James Miller (ed.), Taoism and Ecology. Harvard University Press.

Lederach, J. P. (1995). Preparing for Peace: Conflict Transformation Across Cultures. Syracuse University Press.

Lederach, J. P (1997). Building Peace: Sustainable Reconciliation in Divided Societies. U.S. Institute of Peace.

Lederach, J. P (1999). The Journey Toward Reconciliation. Pennsylvania: Herald Press.

Lederach, J. P (ed.), Sampson, C. (ed.) (2000). From the Ground Up: Mennonite Contributions to International Peacebuilding. USA: Oxford University Press.

Lederach, J. P. (ed.), Jenner, J. M. (ed.) (2002). A Handbook of International Peacebuilding: Into The Eye Of The Storm. USA:Jossey-Bass.

Lederach, J. P. (2003). The Little Book of Conflict Transformation. Pennsylvania: Good Books.

Lederach, J. P. (2005). Moral Imagination: The Art and Soul of Building Peace. USA: Oxford University Press.

Merton, Thomas. (1967). Mystics and Zen Masters, Chapters: Classic Chinese Thought, pp. 45-68, and Love and Tao, pp. 69-80. The Abbey of Gethsemani, Inc.

Merton, Thomas (1968) Zen and the Birds of Appetite, The Abbey of Gethsemani, Inc.

Miall, Hugh (2004) Conflict Transformation: A Multi-Dimensional Task, Berghof Handbook for Conflict Transformation (p. 4). Berghof Research Center for Constructive Conflict

Ming-Dao, Deng. (1996). Everyday Tao: Living with Balance and Harmony (p. viii-x). Harper-Collins.

Rosemont, Henry Jr. (1970). Philosophy East \& West, 20, 63-72. Hawaii: University of Hawaii Press.

Sinaiko, Herman L. (1998). Reclaiming the canon: essays on philosophy, poetry, and history. Yale University Press.

Saso, M. (1985). Chinese Religions. In Hinnells, J. R. (ed.), A Handbook of Living Religions (pp. 344-364). London: Penguin.

Suzuki, D. T. (1955). Studies in Zen (p. 141). London: Rider \& Co.

Suzuki, D. T. (1952). Essays in Zen Buddhism, 2d ser. p. 101. Boston; Beacon Press.

Taoism (n.d) from BBC Religion \& Ethics. Retrieved from http://www.bbc.co.uk/religion

Teilhard de Chardin, Pierre. (1960). Le Milieu Divine. New York: Harper \& Brothers.

Teilhard de Chardin, Pierre. (1965). Hymn of the Universe. New York: Harper \& Brothers.

Yang, C. K. (1961; rpr. 1971). Religion in Chinese society: a study of contemporary social functions of religion and some of their historical factors. University of California Press.

Yum, J. (1988). The impact of Confucianism on interpersonal relationships and communication patterns in east Asia. Communication Monographs, Volume 55, Issue 4.

Zehr, H. (1990). Changing Lenses: A New Focus for Crime and Justice. Pennsylvania: Herald Press.

Zehr, H. (2002). The Little Book of Restorative Justice. Pennsylvania: Good Books. 